Derksen, F., Olde Hartman, T.C., Dijk, A. van, Plouvier, A., Bensing, J., Lagro-Janssen, A. Consequences of the presence and absence of empathy during consultations in primary care:

A focus group study with patients. Patient Education and Counseling: 2016 nivel

\begin{tabular}{|l|l|}
\hline $\begin{array}{l}\text { Postprint } \\
\text { Version }\end{array}$ & 1.0 \\
\hline Journal website & https://linkinghub.elsevier.com/retrieve/pii/S0738-3991(16)30556-0 \\
\hline Pubmed link & $\underline{\text { https://www.ncbi.nlm.nih.gov/pubmed/27989493 }}$ \\
\hline DOI & 10.1016/j.pec.2016.12.003 \\
\hline
\end{tabular}

This is a NIVEL certified Post Print, more info at http://www.nivel.eu

\title{
Consequences of the presence and absence of empathy during consultations in primary care: A focus group study with patients
}

\author{
Frans Derksena, ${ }^{*}$, Tim olde Hartmanb, AnNelies van DijKa, ANnEtTe Plouviera, \\ JOZIEN BENSINGC, ANTOINE LAGRO-JANSSENA \\ a Department Primary and Community Care, Gender \& Women's Health, Radboudumc, \\ Nijmegen, The Netherlands \\ b Department Primary and Community Care, Radboudumc, Nijmegen, The Netherlands \\ c Department of Psychology, Faculty of Social and Behavioural Sciences, Utrecht University. \\ NIVEL (Netherlands Institute for Health Services Research), Utrecht, \\ The Netherlands
}

\begin{abstract}
A B S T R A C T
Objective: There is general consensus that explicit expression of empathy in patient-GP communication is highly valued. Yet, little is known so far about patients' personal experiences with and expectations of empathy. Insight into these experiences and expectations can help to achieve more personcenteredness in GP practice care. Methods: Participants were recruited by a press report in local newspapers. Inclusion criteria: adults, a visit to the GP in the previous year. Exclusion criterion: a formal complaint procedure. Five focus groups were conducted. The discussions were analyzed using constant comparative analysis. Results: In total 28 participants took part in the focus group interviews. Three themes were identified: (1) Personalized care and enablement when empathy is present; (2) Frustrations when empathy is absent; (3) Potential pitfalls of empathy. Participants indicated that empathy helps build a more personal relationship and makes them feel welcome and at ease. Furthermore, empathy makes them feel supported and enabled. A lack of empathy can result in avoiding a visit to the GP. Conclusion: Empathy is perceived as an important attribute of patient-GP communication. Its presence results in feelings of satisfaction, relief and trust. Furthermore, it supports patients, resulting in new coping strategies. A lack of empathy causes feelings of frustration and disappointment and can lead to patients avoiding visiting their GP. Practice implications: More explicit attention should be given to empathy during medical education in general and during vocational GP-training.
\end{abstract}


Derksen, F., Olde Hartman, T.C., Dijk, A. van, Plouvier, A., Bensing, J., Lagro-Janssen, A. Consequences of the presence and absence of empathy during consultations in primary care:

A focus group study with patients. Patient Education and Counseling: 2016

\section{INTRODUCTION}

Explicit expression of empathy on the GP's part is highly valued by the general public and patients alike [1-3]. Patients consulting GPs (General Practitioners) with psychological problems in particular regard empathy and the use of empathic statements by GPs as important aspects of a caring attitude [4,5]. Patients consider empathy to be so important, that recommending a GP to others is strongly associated with the empathic characteristics of that GP [6]. Mercer et al., studying patients' views of the quality of GP consultations, found that the doctor's empathic concern was regarded as one of the core elements of consultations in GP practice [7]. These experiences are all the more interesting because of the mounting evidence that empathy is closely associated with outcomes measures such as lower levels of $\mathrm{HbA} 1 \mathrm{c}$ and LDL-cholesterol in diabetic patients and less severe and shorter lasting common cold symptoms [8,9]. While this literature shows that, a GP's empathy is a core value and major satisfier for patients, not much is known so far about patients' personal experiences with empathy, whether it be positive, or negative ones. In addition, several developments in current GP practice, which possibly influence the above-mentioned aspects, should be taken into account. GPs increasingly have to deal with IT- and administrative requirements. Furthermore, primary care work has increasingly become teamwork, as GPs have to work closely together with other healthcare professionals [10]. These develop-ments require more organizational arrangements and protocols $[11,12]$. To many GPs this protocol-driven care is an important obstacle to showing empathic behaviour [13].

Patients consider GPs to be responsible for the effectiveness of the medical consultation $[2,14]$. It is worth mentioning that, in contrast to patients' opinions about the value of empathy, the GP's focus seems to have shifted to a more task-oriented approach, an emphasis on biomedical factors rather than the patient's emotional aspects, and to productivity and efficiency [15-17].

The concept of empathy can be regarded to be a catch-all one; some scientists and theorists think of empathy as either emerging from more cognitive mechanisms or as an affective process, while others see the emotional and cognitive aspects as overlapping rather than separate [18-21]. Some have made a distinction between 'trait' empathy (parent-infant dyad) versus 'situational' empathy [18,20,22]. To make matters even more confusing, the concepts of empathy, sympathy and compassion are often used interchangeably in today's healthcare literature [23].

Although Macnaughton (medical humanities) has questioned whether a physician can ever really "stand in the patient's shoes" [24], patients, as was stated earlier, on their part highly value empathy. A better understanding of patients' personal experiences with, expectations of and opinions on a GP's empathic behaviour could be instructive for the GP and GP practice at large and may result in more adequate GP practice consultations. However, patients' personal experiences during GP practice consultations and their consequences have so far not been studied thoroughly. Therefore, this qualitative focus group study aims to explore patients' experiences of and opinions on empathy in the encounter In GP practice.

\section{METHODS}

\subsection{Study design}

Five focus group sessions were conducted to explore participants' experiences and opinions with regard to empathy in GP practice. Each focus group consisted of six to 
Derksen, F., Olde Hartman, T.C., Dijk, A. van, Plouvier, A., Bensing, J., Lagro-Janssen, A. Consequences of the presence and absence of empathy during consultations in primary care: A focus group study with patients. Patient Education and Counseling: 2016

seven participants recruited from the general population. Focus group sessions were chosen as a research method, because they rely on group processes, resulting in a deeper exploration and clarification of patients' rationales, expectations and experiences [25]. Furthermore, the size of the individual focus groups allows all participants to express their experiences and opinions [26]. To elicit multiple aspects of empathy, we used a topic guide that was based on literature and expertise of the supervising committee and was tested for appropriateness and usefulness in two pilot focus groups (Appendix A). To progressively focus on the subject of our study, this topic guide was adapted in the course of the first four focus group interviews. The topic guide was further adapted for the fifth focus group (Appendix B).

\subsection{Study population and procedures}

A press report, in which participants were invited to apply for participation, was published in free public local newspapers (including their websites) in four Dutch regions. To ensure a heterogeneous distribution of the sample, we aimed at diversity in sex, age and level of education of participants. As more women and highly educated people responded to the first press report, a second appeal was issued specifically inviting men and people with lower education backgrounds to take part. Adults who had visited their GP at least once in the previous year were included. Persons who had been involved in a formal complaint procedure with a GP were excluded. Thirty persons agreed to participate and met criteria; two of these participants withdrew before the study started, due to illness. Participants were given an explanation of the aims of the study and a guarantee of anonymity and confidentiality by mutual e-mail correspondence. They were also informed of the need to sign an informed consent form. To avoid bias within the group process, the participants within each focus group did not know each other. There was no relationship between researchers and participants prior to study commencement.

\section{[TABLE 1]}

Because of the ongoing debate about the usefulness of mixed or homogenously composed groups [27], we decided to compose one mixed-gender group, three groups with only female participants and one group with only male participants. A significant number of participants turned out to be or have been working in care, as for instance nurses or social workers. As we expected them to have specific perspectives as care-receivers and care-givers, we formed one focus group consisting solely of participants with a care background (see Table 1). The study was approved by the Regional Committee for Medical Research Ethics of the region ArnhemNijmegen (letter dd 10-8- 2015, file number: 2015-330).

\subsection{Data collection}

Each focus group session was moderated by an experienced female moderator with a GP-background (LV). The non-participat-ing group observer (FD) took notes and made audio recordings of the sessions. The sessions lasted 90-110 min and were held at the Radboud university medical centre in November 2015 and March 2016. At the end of each session, the moderator summarized the discussion in order to evaluate the contribution of each of the participants and to establish whether participants agreed with the summary. After each session, the moderator and observer exchanged their preliminary impressions of communication between and participation of the group members. All the participants completed and signed 
Derksen, F., Olde Hartman, T.C., Dijk, A. van, Plouvier, A., Bensing, J., Lagro-Janssen, A. Consequences of the presence and absence of empathy during consultations in primary care: A focus group study with patients. Patient Education and Counseling: 2016

informed consent forms. Participants were offered financial compensation for travel expenses and investment of time (a s 50,-voucher per person).

\subsection{Data analysis}

The observer transcribed the audio recording of each session to obtain a verbatim report. Transcripts of the focus group sessions were imported into qualitative analysis software, Atlas-ti 7. Analysis of the data was performed according to the principles of constant comparative analysis [28]. In order to progressively refine the focus group interview guide to explore the subject in depth, focus group discussions and analysis proceeded iteratively. The data from the two pilot focus groups were analyzed by the GP-researcher with 35 years' experience in general practice (FD) and a female researcher with expertise in qualitative methods (AP). The data from the other five focus groups were analyzed by the same GP-researcher (FD), a female medical student with expertise in qualitative methods (AvD), and a male practicing GP with 10 years' experience in general practice and with expertise in qualitative and quantitative research methods (ToH). During the analysis of the five focus group discussions, researchers (FD, AvD) familiarized themselves with all data by repeatedly reading all the transcripts. Subsequently, applying open coding, the researchers independently unravelled segments of the texts and assigned keywords. Furthermore, every paragraph was thoroughly coded. These codes were compared and discussed several times and the agreed additional codes were applied to the transcripts. Weekly reflective moments were organized. In case of disagreement, the opinion of a third researcher was sought $(\mathrm{ToH})$. Codes referring to the same phenomenon were grouped into categories, and categories were grouped into themes that represent important and relevant aspects of patients' experiences with and opinions on empathy in the clinical encounter. This process was repeated several times. After the fifth focus group, data saturation was reached. The whole process was regularly reflected on and discussed by the entire research team, who read all the verbatim transcripts (FD, JB, ToH, AL). Quotes which underline the main results were presented and were translated by a near-native speaker, from Dutch into English. The consolidated criteria for reporting qualitative studies (COREQ) were applied [28].

\section{RESULTS}

In total 28 patients took part in the focus group discussions. Most of the participants were older than 50, highly educated and female. An overview of the background characteristics of the participants is presented in Table 2. Information on participants' socio-demographic characteristics and their motivation to partici-pate was gathered by means of a questionnaire. The analysis of the focus group interviews revealed that participants described empathy in terms of attitude, competences and behaviour. When speaking about 'attitude', participants mentioned aspects such as a GP's receptivity, commitment and authenticity. With regard to 'competences', participants wanted their GP to take them seriously, to make them feel welcome and to listen to them. A GP's empathic 'behaviour' was described as resulting in feelings of safety, trust and support.The majority of the participants described empathy as an important prerequisite of the GP's commitment and a pivotal characteristic of communication in the GP practice encounter: "To me, empathy is very important. It's a sign of my GP's commitment"(F.FG 5). Furthermore, participants indicated they only felt sincerely listened to when a GP shows empathy: “ . . . because I think that listening is 
Derksen, F., Olde Hartman, T.C., Dijk, A. van, Plouvier, A., Bensing, J., Lagro-Janssen, A. Consequences of the presence and absence of empathy during consultations in primary care:

A focus group study with patients. Patient Education and Counseling: 2016

very important, and also that you feel that it's authentic ... " (C.FG2). Describing their experiences and opinions, participants strong-ly focused on and discussed extensively what consequences the presence or absence of empathy in the GP encounter had on them.

\section{[TABLE 2]}

\subsection{Personalized care and enablement when empathy is present}

According to many participants, empathy in the GP practice encounter facilitates developing a relationship with their GPs from a strictly doctor-patient one to a more person-person one. This more personal relationship made participants feel more at ease, and it also made them feel they were being helped in a more authentic and respectful manner. Participants indicated that their GP's empathic attitude as well as their empathic skills (e.g. creating the right atmosphere for an empathic dialogue) helped build such a relationship.

"For instance, that when you have a complaint, that you feel that your relationship with the GP is such that you can ask questions about it, that you're not afraid to ask questions" (F. FG5).

"I went there with my partner and when the GP asked me 'How have things been for you?' I felt heard and I thought 'Yes, that's a good opening, yes; you've got me on board now'. It made me feel very good" (F.FG4).

As a result of a GP's empathic behaviour (e.g. verbal or non-verbal signals and recognizing patient's feelings) participants described experiences of mutual openness, trust and safety, resulting in better attuned information, mutual understanding and a general feeling of being taken seriously.

"I think it makes you feel like you can be more open, and that can lead to getting what you need sooner, and possibly to a speedier recovery. When I'm more open, he can respond to that with a treatment or a conversation or whatever" (F.FG4).

"It allowed me to trust in her, which enabled me to stop worrying about it all the time .... you don't have to worry all the time about whether things will be OK the next time or about what they're doing to you" (F.FG5).

Additionally, when a GP's empathic behaviour was present, many participants felt they were being supported by their GP. This was important to them in order to develop adequate coping strategies to take control of their own situation. "I had stopped working; my mother had died, and when I came to him complaining about my headaches - in hindsight obviously stress-related - he addressed those issues quite thoroughly, making me think for myself that these things could be related. Talking like that with him a couple of times and getting his advice really helped me through it" (F.FG4).

"She also gave me space to share my feelings and that was kind of confronting at times as well. It made me think about what I wanted and that turned everything around, allowing me to be positive again, to take back control, while taking account of my own feelings" (F.FG5).

\subsection{Frustrations and stress when empathy is absent}

With most participants viewing empathy as quite simply a prerequisite for a successful consultation, they clearly stated that the absence of empathy in the GP 
Derksen, F., Olde Hartman, T.C., Dijk, A. van, Plouvier, A., Bensing, J., Lagro-Janssen, A. Consequences of the presence and absence of empathy during consultations in primary care:

A focus group study with patients. Patient Education and Counseling: 2016

encounter can have a huge impact on the patient-GP relationship; participants become disappointed and feel an emotional distance. Participants indicat-ed that this emotional distance may result in a lack of understanding and can hamper solving the symptoms and problems presented. Additionally, participants reported not feeling respected as unique and equal human beings:

" . . . when I was still with my old GP, I tried to let her know that I felt very uncomfortable with that, with her being so impatient with me. Her response was along the lines of 'she was very busy and I just had to understand that'. To me, that's not empathic at all" (C.FG2).

Participants described they felt frustrated, disempowered, upset, overwhelmed and abandoned, resulting in very stressful consultations. Furthermore, participants reported that they sometimes experienced arrogant, belittling and patronizing behaviour on the part of the GP.

"I felt abandoned, truly abandoned. So much so that it would keep me awake at night, thinking 'how is this gonna be in the future, we're getting on a bit and getting more dependent, can I fall back on her, can I?" (F.FG5).

"... it really feels like falling into a ravine, like being shunted off, which is all the more upsetting because you're already sick and you really can't have something like that when you're sick" (MG.FG1).

Some participants reported they experienced much difficulty in discussing their GP's lack of empathy. Experiencing a lack of empathy sometimes resulted in actions by participants such as writing a letter of complaint or a clarifying visit to the GP. However, in some cases the experienced lack of empathy resulted in avoiding visits to the GP.

"When a doctor shows a lack of empathy, I will consider taking another doctor, for it's very important to me to feel understood" (M.FG3).

Nevertheless participants also made excuses for the GP's non-empathic behaviour, whether on practical grounds (such as lack of time) or on more personal ones. Some participants indicated that they tried to improve their relationship with their GP by showing an interest in their private life.

"There is an age gap, of course-we're a bit older ourselves and that makes you think like 'these younger people have to work so hard, they have to watch the clock all the time and do everything in a rush, with the health insurance companies breathing down their necks', so I'm aware that we're making excuses for their behaviour all the time" (F.FG5).

\subsection{Potential pitfalls of empathy}

Participants indicated that they sometimes experienced negative side effects of empathy. Although most participants regarded empathy as helpful in building a trustful and safe patient-GP relationship, but they were also wary of getting too close and being too open. They felt that too much trust and openness could lead to them sharing too much private information, which could possibly be handled by their GP in an unwelcome manner. Some participants even described how a GP showing what felt to them like excessive empathy could make them feel more concerned about their condition. "When he treated me with so much empathy, I told him things that I later 
Derksen, F., Olde Hartman, T.C., Dijk, A. van, Plouvier, A., Bensing, J., Lagro-Janssen, A. Consequences of the presence and absence of empathy during consultations in primary care: A focus group study with patients. Patient Education and Counseling: 2016

regretted. I can't take them back and I feel certain that he has used that information, to inform a colleague in spite of patient-doctor confidentiality" (M.FG3).

"My suspected infection should have been long over. My doctor was very empathetic, strikingly more so than usual. It scared me" (MG.FG1). Participants also mentioned the possible effects of an excess of empathy on GPs' personal lives. "I think it's in the doctor's best interest not to get too closely involved, for if he does it can easily encroach upon his private life and that shouldn't happen" (MG.FG1).

\section{DISCUSSION AND CONCLUSION}

\subsection{Discussion}

This study clearly shows that participants are very aware of the impact of empathy in the GP practice encounter. Almost all participants stated that the GP showing empathy results in personal patient-GP relationships characterized by openness, trust and safety. Furthermore, it enhances the patient's coping behaviour and leads to a sense of enablement.

An experienced lack of empathy can result in stressful consultations in which participants feel disappointed, upset and overwhelmed. In the long term, a lack of empathy can lead to patients avoiding contact with their GP or even switching to another GP. However, some participants show a willingness to forgive GPs for their shortcomings in showing empathy, mentioning time pressures, red tape or simply not getting along on a personal level as potential reasons.

Participants also mentioned potential pitfalls of the use of empathy. An empathic approach by the GP can lead to the patient sharing what is later felt as too much private information, and even to anxiety about their condition.

Higher perceived GP empathy has been discussed recently as a significant independent predictor of symptom improvement a month after consultation [29]. Furthermore, empathy strongly influences the interpersonal motivation of individuals to approach each other, and it guides social interaction and shapes relation- ships [30].

Our results provide a deeper insight into these aspects, as participants show how they observe and are very aware of the consequences of a lack of empathy in the primary care encounter. In spite of these negative consequences participants look for excuses - time pressure, red tape or personal differences - for the GPs' shortcomings. Recently Mazzi et al. have shown that patients consider sharing responsibility and behaving respectfully towards each other to be important within the patient-GP relationship [31].

Additionally, patient loyalty - the patient's deeply felt commit-ment to GPs despite situational influences and marketing efforts - is strongly related to patient trust, good patient-GP relationships and patient satisfaction [32]. Our results suggest that the search for excuses by patients can be attributed to their loyalty; they protect their patient-GP relationship. However, one of the key issues raised in this study is that patient loyalty is not infinite. Participants indicate that a lack of empathy results in a difficult situation and can even result in avoidance of the GP or the decision to transfer to another GP, leading to obstacles in the path to adequate continuing primary care. Only Halpern, referring to medical care in a broad sense, discussed the possibility of patients transferring to other physicians as a possible result of a lack of 
Derksen, F., Olde Hartman, T.C., Dijk, A. van, Plouvier, A., Bensing, J., Lagro-Janssen, A. Consequences of the presence and absence of empathy during consultations in primary care: A focus group study with patients. Patient Education and Counseling: 2016

emotion in a physician's communication [33]. Other studies have shown that a lack of empathy can lead to disappointment with the healthcare system [34] or to an increase of malpractice suits [35]. We have identified two other aspects of how GPs' empathic behaviour affects patients' experiences. Firstly, we found that patients can experience empathy as a 'trap'. Observational studies have found a GP's empathic and emotionally attuned behaviour can lead to receiving more detailed information about the patient's condition [33,36,37]. However, some of our participants expressed concern at being tempted to share too much private information. Moreover, some of them worried about how this information is handled. Also, it appeared that what is perceived by patients as an excess of GP empathy can result in them feeling more concerned about their condition. These findings are in line with the statement of Konrath et al. In their recent review [18] they stated that "although empathy is nearly always a desirable attribute in relationships, it can have some apparently contradictory results". Therefore, professionals should be aware of the limits of empathy and take responsibility to protect patients' boundaries [18]. Secondly, participants feel that the presence of empathy within the encounter in GP practice makes them feel supported results of their search of adequate coping strategies. Recently, Mercer et al. found that enablement - the extent to which a patient, after a medical consultation, feels able to cope with, understand and manage his/her illness - does not occur when the patient perceives low levels of empathy in the doctor; they suggested that a GP's empathy is a basic prerequisite for patient enablement [38]. Empathy is considered by them as one of the consultation factors associated with enablement. However, they do not discuss the connection between these two concepts in a detailed manner. Elaborating on this theme we hypothesize that a triangle between empathy, trust and enablement exists in consultations in GP practice. GP practices and the long-term patient-GP relationship on their own are regarded as important catalytic agents to identify patients' strengths [39,40]. Empathy especially helps the GP to reach the patient in his/her illness and to value the patient as a person $[14,41]$. Owing to this, the patient's sense of trust, self-control and of being known increases [14], and these feelings of control and self-confidence activate the development of adequate coping strategies [42]. These assump tions are elucidated by our study's results and resemble the salutogenetic perspective which underpins the importance of acknowledging the patient as a person who is able to manage the situation him/herself and to mutually engage professionals and patients in a process [43].

\section{CONCLUSION}

Whenever empathy is present in patient-GP communication, patients feel heard and supported, which contributes to a trustful and effective patient-GP relationship and to new coping strategies. If empathy is absent, patients experience stress and other negative feelings during and after consultations. These feelings result in patients avoiding their GP, which can make it difficult for patients to get adequate GP practice care. Patients sometimes make excuses for GPs' shortcomings in empathetic communication.

\section{Practice implications}

The narrative picture of the participants' positive emotions caused by the presence of empathy (increased personalized care, trust and support of coping strategies) and the 
Derksen, F., Olde Hartman, T.C., Dijk, A. van, Plouvier, A., Bensing, J., Lagro-Janssen, A. Consequences of the presence and absence of empathy during consultations in primary care: A focus group study with patients. Patient Education and Counseling: 2016

negative emotions caused by the absence of empathy (disappointment and avoidance of visiting a GP) should guide GPs towards patient-GP communication in which empathy is a core element.

Furthermore, the study's results might provide instructive material for medical education. GPs, residents and medical students should be educated in more detail on how to use empathy as a tool to increase the beneficial effects of the consultation and to enable patients to develop adequate coping strategies. They should also be educated to be aware of potential pitfalls of using empathy. At present, during vocational GP training, empathy in patient-GP communication is mostly dealt with implicitly in training communication skills $[44,45]$ and we hope that this study shows the urgent need for more explicit attention to empathy in GP education. During GP education only self-rated measures of empathy are applied [46]; because of the instructiveness of the patients' experiences with empathy we suggest applying the patient-rated CARE-measure as well $[46,47]$. Strength of this study is its founding in daily GP practice. Focus group discussions allowed participants to share their stories and opinions and to express themselves freely. This revealed valuable insights into person-centred elements of the affective side of communication in GP practice. Tape-recording the discussion, evaluating and checking the participants' contributions at the end of each session and multiple coding during the analysis added to the rigor of the study. However, there are some limitations to discuss. The qualitative data collected through the focus group interviews lack narratives of lower educated participants. Although the research team was aware of the lack of male and lower educated participants and actively tried to redress this imbalance, we did not fully succeed in this. It is possible that patients who were not accessed by this study view empathy differently from the slightly older, mostly female, middle class participants who took part.

Furthermore, with the moderator, focus group observer and analysers all having a GP-background, our interpretation of the data might be slightly biased. However, we are convinced that by including a behavioural scientist in the supervising committee (JB) this potential bias has been sufficiently redressed. As in all qualitative research, the purposive sample does not represent the views of the general population.

However, it does represent a broad range of opinions in the population with regard to empathy in the GP practice encounter.

\section{CONFLICT OF INTEREST}

No funding was obtained for this study. The authors have no conflicts of interest to declare.

\section{AUTHORS' CONTRIBUTIONS}

FD, JB, ToH and AL contributed to the concept and design of the study. FD, AP and AvD analyzed the data. FD, ToH, JB and AL drafted the manuscript and provided substantial input into revisions of the manuscript. All authors approved the final manuscript.

\section{ACKNOWLEDGEMENTS}

We would like to thank the participants for their time and for sharing their personal experiences, Loes Veraart for moderating the focus group discussions and Judith Tijman for editing and translation. 
Derksen, F., Olde Hartman, T.C., Dijk, A. van, Plouvier, A., Bensing, J., Lagro-Janssen, A. Consequences of the presence and absence of empathy during consultations in primary care:

A focus group study with patients. Patient Education and Counseling: 2016

\section{APPENDIX A. : INTERVIEW GUIDELINES FOCUS GROUP.}

\section{Introduction by the moderator:}

A warm welcome to all. I will first introduce myself, I am ... During this focus group I will function as a moderator. This means that I will present to you questions and that I will try, as far as possible, that anyone can speak freely. I will appoint you with the first name, that seems excessive, but is important for the elaboration of the audio tapes in finding who has said something. With this you takes part in a scientific research on empathy in communication between general practitioners and people who use general practice care. It is a qualitative form of research and takes place in the form of several focus groups. A focus group is a group of 6-7 participants who are found to be participate under the direction of a moderator and who want to talk about a topic together. This includes researching, identifying and describing the experiences and opinions of the participants. Within our research there will be organized multiple focus groups.

We are looking for the greatest possible diversity of opinions on this topic, so both positive and negative. We find everyone's opinion important; therefore I would ask you not to talk to each other and to wait with a reaction until someone has ended. So feel free to report your experience or opinion; today you are the 'expert'. The entire conversation becomes audio recorded. You can be sure that the recordings will be treated strictly confidential. To indicate that you have understood everything and has no objection for the scientific use of the data you will first be asked to sign a form before that (we call that a "informed consent").

We are very grateful that you participate in this part of the research. The meeting takes about $11_{1} / 2$ hour, briefly paused halfway. If there are no further questions you can now complete and sign the form of "informed consent".

My 1 st question is a ' one by one ' question; just some more explanation can be asked. The other questions are ' interaction questions '; You can directly interact. Questions:

1. Would you like to say who you are, would you tell something in brief about yourself, and why you are motivated to talk about empathy.

2. We're talking today about empathy. You may have thought about the subject. We are interested in how you defines it. Could you describe what empathy means for you. What is that anyway? You can also describe it with examples.

3. When we talk about a GP's empathy, can you describe your own experiences? Do you have examples in negative or positive sense?

4. Do you have an opinion about or could you define what influence empathy has on communicating with your GP?

Hereafter the moderator gives a brief summary of the answers ot the key questions and the emerging ideas during the discussion and verifies that all group members find this an adequate summary.

_ Do you have any important opinions or comments about the issues discussed that you missed and you'd like to share? 
Derksen, F., Olde Hartman, T.C., Dijk, A. van, Plouvier, A., Bensing, J., Lagro-Janssen, A. Consequences of the presence and absence of empathy during consultations in primary care:

A focus group study with patients. Patient Education and Counseling: 2016

\section{APPENDIX B. : INTERVIEW GUIDELINE FOCUS GROUP 5.}

\section{Introduction by the moderator:}

A warm welcome to all. I will first introduce myself, I am ... During this focus group I will function as a moderator. This means that I will present to you questions and that I will try, as far as possible, that anyone can speak freely. I will appoint you with the first name, that seems excessive, but is important for the elaboration of the audio tapes in finding who has said something. With this you takes part in a scientific research on empathy in communication between general practitioners and people who use general practice care. It is a qualitative form of research and takes place in the form of several focus groups. A focus group is a group of 6-7 participants who are found to be participate under the direction of a moderator and who want to talk about a topic together. This includes researching, identifying and describing the experiences and opinions of the participants. Within our research there will be organized multiple focus groups. We are looking for the greatest possible diversity of opinions on this topic, so both positive and negative. We find everyone's opinion important; therefore I would ask you not to talk to each other and to wait with a reaction until someone has ended. So feel free to report your experience or opinion; today you are the 'expert'. The entire conversation becomes audio recorded. You can be sure that the recordings will be treated strictly confidential. To indicate that you have understood everything and has no objection for the scientific use of the data you will first be asked to sign a form before that (we call that a "informed consent"). Within our study four focus groups have been organized until now. Their results have been analyzed; this analysis has lead to some subjects who need more detailed discussion with people. So we have some further questions. We are very grateful that you participate in this part of the research. The meeting takes about $1, / 2$ hour, briefly paused halfway. If there are no further questions you can now complete and sign the form of "informed consent". My 1 st question is a ' one by one ' question; just some more explanation can be asked. The other questions are ' interaction questions '; You can directly interact. Questions: 1. Would you like to say who you are, would you tell something in brief about yourself, and why you are motivated to talk about empathy. 2. We're talking today about empathy. You may have thought about the subject. We are interested in which positive and negative effects of empathy you experience; can you describe it and do you have examples. _ So, which are the positive effects of empathy during GP-consultation? 3. And which negative effects of empathy do you experience consulting a GP? 4. Within other focus groups absence of empathy or wrong use of empathy by the GP has been discussed. Do you recognize this? Do you have examples or descriptions? Which are the consequences of such a GP's behaviour? 5. Can you describe your own influence on the GP's empathic behaviour? Do you consider this important? And why? _ So entering the GP's practice which are your own oppor- tunities to look after empathic GP's communication and which own behaviour should you prevent? Hereafter the moderator gives a brief summary of the answers on the key questions and the emerging ideas during the discussion and verifies that all group members find this an adequate summary. _ Do you have any important opinions or comments about the issues discussed that you missed and you'd like to share? 
Derksen, F., Olde Hartman, T.C., Dijk, A. van, Plouvier, A., Bensing, J., Lagro-Janssen, A. Consequences of the presence and absence of empathy during consultations in primary care: A focus group study with patients. Patient Education and Counseling: 2016

\section{REFERENCES}

[1] J.M. Bensing, M. Deveugele, F. Moretti, I. Fletcher, L. van Vliet, M. Van Bogaert, et al., How to make the medical consultation more successful from a patient's perspective? Tips for doctors and patients from lay people in the United Kingdom, Italy, Belgium and The Netherlands, Patient Educ. Couns. 84 (3) (2011) 287-293.

[2] M.A. Mazzi, J. Bensing, M. Rimondini, I. Fletcher, L. van Vliet, C. Zimmermann, et al., How do lay people assess the quality of physicians' communicative responses to patients' emotional cues and concerns? An international multicentre study based on videotaped medical consultations, Patient Educ. Couns. 90 (3) (2013) 347-353.

[3] J. Bensing, M. Rimondini, A. Visser, What patients want, Patient Educ. Couns. 90 (3) (2013) 287-290.

[4] M. Buszewicz, N. Pistrang, C. Barker, J. Cape, J. Martin, Patients' experiences of GP consultations for psychological problems: a qualitative study, Br. J. Gen. Pract. 56 (528) (2006) 496-503.

[5] M. Quirk, K. Mazor, H.L. Haley, M. Philbin, M. Fischer, K. Sullivan, et al., How patients perceive a doctor's caring attitude, Patient Educ. Couns. 72 (3) (2008) 359-366.

[6] P. Vedsted, H.N. Heje, Association between patients' recommendation of their GP and their evaluation of the GP, Scand. J. Prim. Health Care 26 (4) (2008) 228-234.

[7] S.W. Mercer, P.G. Cawston, A.P. Bikker, Quality in general practice consultations; a qualitative study of the views of patients living in an area of high socio-economic deprivation in Scotland, BMC Fam. Pract. 8 (2007) 22.

[8] M. Hojat, D.Z. Louis, F.W. Markham, R. Wender, C. Rabinowitz, J.S. Gonnella, Physicians' empathy and clinical outcomes for diabetic patients, Acad. Med. 86 (3) (2011) 359-364.

[9] D. Rakel, B. Barrett, Z. Zhang, T. Hoeft, B. Chewning, L. Marchand, et al., Perception of empathy in the therapeutic encounter: effects on the common cold, Patient Educ. Couns. 85 (3) (2011) 390-397.

[10] J.P. Geyman, Disease management: panacea, another false hope, or something in between? Ann. Fam. Med. 5 (3) (2007) 257-260.

[11] K.C. Stange, The problem of fragmentation and the need for integrative solutions, Ann. Fam. Med. 7 (2) (2009) 100-103.

[12] K.C. Stange, R.L. Ferrer, The paradox of primary care, Ann. Fam. Med. 7 (4) (2009) 293-299.

[13] F. Derksen, J. Bensing, S. Kuiper, M. van Meerendonk, A. Lagro-Janssen, Empathy: what does it mean for GPs? A qualitative study, Fam. Pract. (2014).

[14] J.G. Scott, D. Cohen, B. Dicicco-Bloom, W.L. Miller, K.C. Stange, B.F. Crabtree, Understanding healing relationships in primary care, Ann. Fam. Med. 6 (4) (2008) 315322.

[15] Spiro H. Commentary, The practice of empathy, Acad. Med. 84 (9) (2009) 1177- 1179.

[16] B.A. Lown, A social neuroscience-informed model for teaching and practising compassion in health care, Med. Educ. 50 (3) (2016) 332-342.

[17] L. Butalid, P.F. Verhaak, H.R. Boeije, J.M. Bensing, Patients' views on changes in doctor-patient communication between 1982 and 2001: a mixed-methods study, BMC Fam. Pract. 13 (2012) 80.

[18] S. Konrath, D. Grynberg, The positive and negative psychologie of empathy, in: D.P.J. Watt (Ed.), Psycholgy and Neurobiology of Empathy, Nova Science Publishers, New York, 2013.

[19] F. Deutsch, R.A. Madle, Empathy: historic and current conceptualizations, measurement, and a cognitive theoretical perspective, Hum. Dev. 18 (4) (1975) 267-287.

[20] D. Watt, Toward a neuroscience of empathy: integrating affective and cognitive perspectives, Interdiscip. J. Psychoanal. Neurosci. 9 (2) (2007) 119-140.

[21] M. Hoffman, Interaction of Affect and Cognition in Empathy, Canbridge University Press, 1984.

[22] S.D. Preston, The origins of altruism in offspring care, Psychol. Bull. 139 (6) (2013) 1305-1341.

[23] S. Sinclair, K. Beamer, T.F. Hack, S. McClement, S. Raffin Bouchal, H.M. Chochinov, et al., Sympathy, empathy, and compassion: a grounded theory study of palliative care patients' understandings, experiences, and preferences, Palliat. Med. (2016). 
Derksen, F., Olde Hartman, T.C., Dijk, A. van, Plouvier, A., Bensing, J., Lagro-Janssen, A. Consequences of the presence and absence of empathy during consultations in primary care: A focus group study with patients. Patient Education and Counseling: 2016

[24] J. Macnaughton, The dangerous practice of empathy, Lancet 373 (9679) (2009) 19401941. [25] D.L. Morgan, Focus Groups as Qualitative Research, 2nd edition, Sage, London, 1997.

[26] T. Freeman, 'Best practice' in focus group research: making sense of different views, J. Adv. Nurs. 56 (5) (2006) 491-497.

[27] D.W. Stewart, P. Shamdasani, Focus Groups Theory and Practice, third edition ed., Sage, 2014.

[28] D.J. Cohen,B.F. Crabtree, Evaluative criteria for qualitative research inhealthcare: controversies and recommendations, Ann. Fam. Med. 6 (4) (2008) 331-339.

[29] S.W. Mercer, M. Higgins, A.M. Bikker, B. Fitzpatrick, A. McConnachie, S.M. Lloyd, et al., General practitioners' empathy and health outcomes: a prospective observational study of consultations in areas of high and low deprivation, Ann. Fam. Med. 14 (2) (2016) 117-124.

[30] P.A. Van Lange, Does empathy trigger only altruistic motivation? How about selflessness or justice?, Emotion (Washington DC) 8 (6) (2008) 766-774.

[31] M.A. Mazzi, M. Rimondini, W.G. Boerma, C. Zimmermann, J.M. Bensing, How patients would like to improve medical consultations: insights from a multicentre European study, Patient Educ. Couns. 99 (1) (2016) 51-60.

[32] E.A. Platonova, K.N. Kennedy, R.M. Shewchuk, Understanding patient satisfaction, trust, and loyalty to primary care physicians, Med. Care Res. Rev.: MCRR 65 (6) (2008) 696-712.

[33] J. Halpern, From idealized clinical empathy to empathic communication in medical care, Med. Health Care Philos. 17 (2) (2014) 301-311.

[34] E. Gilbert, J.M. Ussher, J. Perz, K. Hobbs, L. Kirsten, Positive and negative interactions with health professionals: a qualitative investigation of the experiences of informal cancer carers, Cancer Nurs. 33 (6) (2010) E1-9. [35] J. Halpern, Empathy and patient-physician conflicts, J. Gen. Intern. Med. 22 (5) (2007) 696-700.

[36] F. Derksen, J. Bensing, A. Lagro-Janssen, Effectiveness of empathy in general practice: a systematic review, Br. J. Gen. Pract. 63 (606) (2013) e76-e84.

[37] A. Finset, T.A. Mjaaland, The medical consultation viewed as a value chain: a neurobehavioral approach to emotion regulation in doctor-patient interaction, Patient Educ. Couns. 74 (3) (2009) 323-330.

[38] S.W. Mercer, B.D. Jani, M. Maxwell, S.Y. Wong, G.C. Watt, Patient enablement requires physician empathy: a cross-sectional study of general practice consultations in areas of high and low socioeconomic deprivation in Scotland, BMC Fam. Pract. 13 (2012) 6.

[39] I. Holmstrom, M. Roing, The relation between patient-centeredness and patient empowerment: a discussion on concepts, Patient Educ. Couns. 79 (2) (2010) 167-172.

[40] E. Mola, J.A. De Bonis, R. Giancane, Integrating patient empowerment as an essential characteristic of the discipline of general practice/family medicine, Eur. J. Gen. Pract. 14 (2) (2008) 89-94.

[41] R. Charon, The patient-physician relationship narrative medicine: a model for empathy, reflection, profession, and trust, JAMA 286 (15) (2001) 1897-1902.

[42] A. Girgis, R.W. Sanson-Fisher, Breaking bad news 1: current best advice for clinicians, Behav. Med. (Washington, DC) 24 (2) (1998) 53-59.

[43] B. Lindstrom, M. Eriksson, Contextualizing salutogenesis and Antonovsky in public health development, Health Promot. Int. 21 (3) (2006) 238-244.

[44] G. Essers, The communication wheel. Available from: http://www.hovumc.nl/ docs/silverman/communicatiewiel.html. [45] F. Tromp, How to assess progress in competency-based postgraduate medical training, Radboud University, Nijmegen, 2014. [46] J.M. Hemmerdinger, S.D. Stoddart, R.J. Lilford, A systematic review of tests of empathy in medicine, BMC Med. Educ. 7 (2007) 24.

[47] S.W. Mercer, M. Maxwell, D. Heaney, G.C. Watt, The consultation and relational empathy (CARE) measure: development and preliminary validation and reliability of an empathy-based consultation process measure, Fam. Pract. 21 (6) (2004) 699-705. 
Derksen, F., Olde Hartman, T.C., Dijk, A. van, Plouvier, A., Bensing, J., Lagro-Janssen, A. Consequences of the presence and absence of empathy during consultations in primary care: A focus group study with patients. Patient Education and Counseling: 2016

\section{TABLES AND FIGURES}

Table 1

Arrangement of the focus groups.

\begin{tabular}{clll}
\hline Focus group number & Type, Abbreviation & Gender & Specific characteristics \\
\hline 00 & Pilot & Mixed & \\
0 & Pilot & Mixed & \\
1 & MG.FG1 & Mixed & \\
2 & C.FG2 & Female & Care background \\
3 & M.FG3 & Male & \\
4 & F.FG4 & Female \\
5 & F.FG5 & Female \\
\hline
\end{tabular}

Table 2

Characteristics of 28 participants of the study.

\begin{tabular}{ll}
\hline characteristics & $\mathrm{N}(\%)$ \\
\hline Gender & \\
Male & $9(32)$ \\
Female & $19(68)$ \\
& \\
Educational level & \\
Low & $0(0)$ \\
Middle (MBO) & $8(28)$ \\
High (HBO and Univ.) & $20(72)$ \\
Age categories & \\
$<50$ & \\
$50-65$ & $3(10)$ \\
$>65$ & $13(47)$ \\
Occupation & $12(43)$ \\
Education & \\
Services & $5(19)$ \\
Care & $15(55)$ \\
\hline
\end{tabular}

